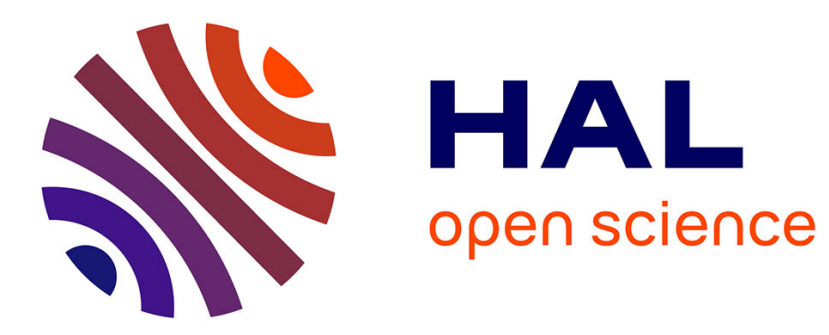

\title{
Culture, Utility or Social Systems? Explaining the Cross-National Ties of Emigrants from Borşa, Romania Christina Boswell, Oana Ciobanu
}

\section{To cite this version:}

Christina Boswell, Oana Ciobanu. Culture, Utility or Social Systems? Explaining the Cross-National Ties of Emigrants from Borşa, Romania. Ethnic and Racial Studies, 2009, 32 (8), pp.1346-1364. 10.1080/01419870802245026 . hal-00521093

\section{HAL Id: hal-00521093 https://hal.science/hal-00521093}

Submitted on 25 Sep 2010

HAL is a multi-disciplinary open access archive for the deposit and dissemination of scientific research documents, whether they are published or not. The documents may come from teaching and research institutions in France or abroad, or from public or private research centers.
L'archive ouverte pluridisciplinaire HAL, est destinée au dépôt et à la diffusion de documents scientifiques de niveau recherche, publiés ou non, émanant des établissements d'enseignement et de recherche français ou étrangers, des laboratoires publics ou privés. 


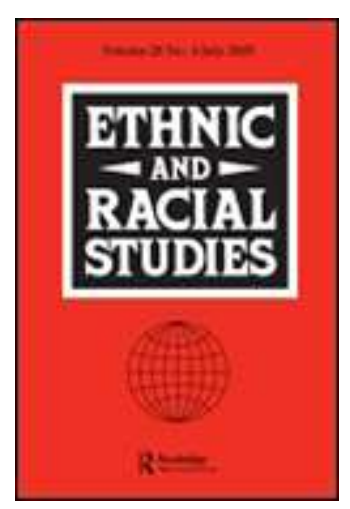

\section{Culture, Utility or Social Systems? Explaining the Cross- National Ties of Emigrants from Borşa, Romania}

\begin{tabular}{|r|l|}
\hline Journal: & Ethnic and Racial Studies \\
\hline Manuscript ID: & RERS-2007-0110.R2 \\
\hline Manuscript Type: & Original Manuscript \\
\hline Keywords: & $\begin{array}{l}\text { Transnationalism, Migration, Immigrant Mobility, integration, } \\
\text { Migrant networks, Romania }\end{array}$ \\
\hline
\end{tabular}

\section{s ScholarONE" \\ Manuscript Central}




\title{
Culture, Utility or Social Systems? \\ Explaining the Cross-national Ties of Emigrants from Borşa, Romania
}

Christina Boswell and Oana Ciobanu

\begin{abstract}
Emigrants from Borşa, Romania, display two quite distinct patterns of ties with their community of origin: migration to Italy is discernibly transnational, with a strong reliance on migrant networks; while migration to the UK is more individualistic, with emigrants shunning interaction with compatriots and retaining only weak ties to Borşa. We argue that prevalent theories of cross-national ties fail adequately to explain this divergence. Instead, we draw on systems theory to explain the discrepancy in terms of divergent conditions for societal inclusion. In Italy, incorporation into parallel, unofficial structures of work, welfare and accommodation encouraged a reliance on cultural criteria for maintaining social ties. In the UK, migrants were obliged to integrate into state-sponsored systems, encouraging the relinquishing of ethnic ties in favour of more strategic networking to facilitate societal inclusion.
\end{abstract}

Keywords: Culture of migration; transnational migration; migrant networks; social interactions; Romanian migration; irregular migration. 
Much of the recent literature on international migration has focused on patterns of social interaction between migrants and communities of origin. Such interactions have been explained by drawing on three different, but not mutually incompatible, theories. The first is what can be termed a 'cultural embeddedness' approach, which emphasizes the way in which specific cultural norms and beliefs in the community of origin shape subsequent social ties. Second is the notion of transnationalism, which sets out the macro- and meso- conditions facilitating the retention of social, economic and political ties between emigrants and their communities of origin. And the third is the concept of migrant networks, most comprehensively theorized by rational choice theorists, which explains the retention of ties in terms of individual calculations of costs and opportunities.

The Romanian town of Borşa offers an interesting case for exploring the explanatory power of these different theories. The town has been the source of two rather different emigration flows. The first group, clustered in Milan, bears the hallmarks of a culturally shaped pattern of cross-national social ties, which has evolved into transnationalism. Migrants retain close ties with the place of origin, and circular migration has become normalized as a strategy for enhancing economic and social status. By contrast, a second group of Borşa residents who have migrated to London display a rather different pattern of interaction with their fellow townspeople. Although sharing a similar social-cultural background and possibilities for retaining cross-national ties, their strategies can be observed as far more individualistic, and more reflexively responsive to the structure of opportunities in the place of destination. These migrants shun contacts with fellow Borşeni and co-nationals, preferring networks that can facilitate integration into the UK labour or housing markets. The retention of ties based on shared origin or ethnicity is seen to be unhelpful, even burdensome.

On first examination, these differences appear to be best explained by rational choice theories. Opportunities in the place of origin ostensibly have far more causal weight than do 
either cultural features of emigrants and their communities, or the conditions assumed to facilitate transnationalism. We argue, however, that the case of Borşa also reveals some of the short-comings of rational choice theories. While these theories are correct to emphasize opportunity structures in host countries, they under-theorize the relevance of what we call the conditions of societal inclusion. Drawing on recent contributions from systems theory, we argue that the contrast between the two cases can at least in part be explained in terms of the different requirements for societal incorporation in the two societies (Bommes and Tacke 2006b). In the case of Italy, migrants integrate into parallel, informal structures, encouraging a dependence on ethnic or kinship ties as a basis for societal inclusion. By contrast, migrants to the UK found they needed to adopt strategies to integrate into functionally differentiated systems, inclusion into which depended on certain skills and behaviour, rather than a pregiven status or identity. This account implies the need for a more rigorous theory of how the requirements of societal inclusion affect both strategies of mobility, and migrant networks.

The paper is divided into three parts. The first part sets out the three main theories typically deployed to understand the factors shaping patterns of social ties between emigrants and their places of origin. The second part presents empirical findings on emigration from Borşa, and considers how far these support the different theoretical approaches. In a final section, we relate suggest how existing accounts could be supplemented by a theory of the conditions for societal inclusion.

It should be noted that our empirical data is not exhaustive, and the single case of Borşa cannot provide a basis for generalization. As such, the findings do not offer conclusive evidence for privileging one theory over another, but should instead be considered as an initial plausibility probe, which at least prima facie lends support to the systems theory approach. The main contribution of the article, we hope, is to demonstrate the explanatory 
potential of this approach, though clearly further research is needed to refine and test its claims.

\section{Theorizing Cross-national Ties}

There are diverse ways of theorizing the scope and content of social ties between emigrants and their places of origin. In this paper we distinguish between three types of explanation which might help account for divergent patterns in such ties.

The first of these is what can be labelled the 'cultural embeddedness' approach, which put the onus of explanation on socio-cultural characteristics of the community of origin (for recent discussions, see Fuglerud and Engebrigtsen 2006; Evergeti and Zontini 2006). On this account, patterns of social interaction between emigrants and their communities of origin are shaped by a system of norms and beliefs particular to that community. These may include notions about the desirability of migration; which sorts of people should migrate; what duties of loyalty are owed to the place of origin; or what sorts of mutual support one should expect from other emigrants.

Where such norms and beliefs are sufficiently detailed, comprehensive and widespread, we can refer to them as a 'culture of migration' (Massey et al. 1998; Kandel and Massey 2002; Heering et al. 2004). Cultures of migration are discourses that are internalized by members of the community, and which influence not just decisions on mobility, but patterns of interaction between emigrants and communities of origin. They generate expectations about appropriate patterns of interaction, including the desirability of migration or return, and the scope and content of bonds between emigrants and those left behind. For our purposes, the key feature of these theories is that the weight of causality lies in cultural 
features of the community of origin, which largely determine subsequent interactions between migrants and places of origin.

The second way of theorizing these ties emanates from literature on transnationalism (Glick Schiller et al. 1995; Portes et al. 1999; Kivisto 2001; Vertovec 2003). Transnationalism can be characterized as the retention of close social, economic, political and symbolic ties between migrants and places of origin. Such theories offer a more applied set of hypotheses for explaining the emergence and persistence of a rather distinct type of cross-national interaction: namely, one in which emigrants 'live dual lives, speaking two languages, having homes in two countries, and make a living through continuous regular contact across national borders' (Portes et al. 1999, p. 217). Portes argues that necessary conditions for transnationalism include the ease of mobility and communication between places of origin and destination, as well as the political context of emigration and the receptivity of the host society (Portes et al. 1999; 2003). Faist makes similar points, emphasizing the role of integration policies in shaping transnationalism (Faist 2000, p. 198).

This account is not incompatible with culturally embedded accounts. However, it emphasizes the explanatory role of a wider array of factors: not just socio-cultural characteristics of communities engaged in transnationalism (though this is important), but also social and political conditions in receiving countries, as well as ease of communications between the two. In this sense, it offers a more applied theory, developed to explain an empirical phenomenon which, most authors claim, has expanded under the particular conditions of globalization (Levitt et al. 2003, p. 569). The approach also borrows certain elements from theories of networks (Vertovec 2003).

The third way of understanding the role of social ties is far more utilitarian. On this account, social interaction between emigrants and home communities can be understood as a rational calculation of expected costs and benefits. This calculation may be made at the level 
of individual or household (Stark 1991; Stark and Bloom 1985). In both cases, however, it is driven by an interest in utility maximization, and informed by available information on the best means of achieving this. Rational choice accounts do not exclude the possibility that social ties may influence these decisions (Granovetter 1985; Manski 2000). Indeed, many contributions have sought to explain the role of social ties in rational choice terms (Radu 2008; Boswell 2008). A key concept here is that of migrant networks, which comprise a set of social connections that can reduce the costs of migration and integration (Epstein and Gang 2004, p. 6).

While network theory has tended to focus on the role of social ties in facilitating and perpetuating mobility, it can also help explain patterns of interaction subsequent to migration. The retention of ties with fellow emigrants can help with economic and social integration, thereby reducing the costs migration. Moreover, networks with those in the place of origin can be attractive as a means of spreading risk, channelling investments, preparing an eventual return, or facilitating contacts with potential future emigrants. In short, as Massey and associates write, 'networks make international migration extremely attractive as a strategy for risk diversification or utility maximisation' (Massey et al. 1998, p. 43). However, in contrast to the cultural embeddedness account, the shape and content of these ties are not determined by shared norms and beliefs. Rather, they are responsive to the structure of costs and opportunities in places of destination (Epstein and Gang 2004). Thus the level of interaction with the place of origin will vary depending on the expected contribution of such ties to promoting individual or household utility.

We can summarize the main features of the three accounts as follows.

- The basic assumption of the cultural embeddedness account is that migration decisions are shaped by socio-cultural features of the community. They cannot be explained in terms of generalizable features common to all individuals (rationality, utility 
maximization), but emerge as a response to quite specific historical and cultural conditions. These can evolve into a culture of migration, a set of norms and beliefs that influence patterns of cross-national ties.

- $\quad$ Transnationalist accounts seek to explain a specific and (arguably) quite recent phenomenon: the persistence of close ties between emigrants and communities of origin. This pattern of cross-national interaction is explained not just with reference to cultural characteristics of migrants, but also in terms of technological developments such as ease of travel and communication, and social and political conditions in host countries.

- $\quad$ By contrast, rational choice accounts assume that patterns of interaction between emigrants and communities of origin are ultimately explicable in terms of rational individual (or household) choices. These are in turn influenced by the structure of opportunities in host countries, which shape immigrants' decisions on what sorts of networks to develop. The scope and intensity of migrant networks will therefore adjust according to changes in opportunities in places of destination.

\section{Emigration from Borşa}

In order to explore the plausibility of these different theories, we examine the case of emigration from Borşa, a small town in northern Romania. The fieldwork we are drawing on consisted of fifteen in-depth interviews with migrants and their contacts in Borşa; four interviews with the local authorities; and three focus groups with women, high school students and unemployed residents. It was conducted in the autumn of 2004. Before presenting the findings, we shall provide some general background information on Borşa. 
The town of Borşa is an administrative unit with a population of 27,021 (as measured in the 2002 Census). It has one of the highest rates of emigration in Romania, with by far the largest group migrating to Italy, but a considerable and increasing proportion moving to the UK. During the communist era, Borşa was an important industrial centre, with a gold mine that provided the bulk of employment opportunities. However, in the early 1990s the mines were closed as part of a programme of economic restructuring, and unemployment rose rapidly.

The first significant wave of international migration occurred from 1991-2, directed towards Germany and Austria. This movement was mainly confined to those with contacts to ethnic German residents (Aussiedler), who had already migrated in the 1960s-1970s. Borşeni were able to obtain visas through receiving invitations from those already in Germany or Austria, who facilitated their stay once there. More widespread emigration began in 1997, which saw the first redundancies of miners. Younger employees were the first to accept redundancy packages. Many of the older workers chose to keep working, in the hope that they would be entitled to a full pension by the time the company closed. The effect of laying off miners on international migration was two-fold: on the one hand, it provided the necessary resources to finance movement, and on the other hand it generated a rapid increase in the number of young people searching for new economic opportunities and prepared to leave. From 1997 onwards Italy clearly emerged as the most important country of destination. A second destination that became significant from 2000 - 2002 was the UK, and especially London. Estimates of the total level of international migration vary significantly. In interviews, estimates range from $3-4,000$ to $10-15,000$ individuals, between $1989-2004$. In spite of the similar circumstances of emigration, however, there is a significant difference between patterns of migration to Italy and to the UK. 
Migration to Italy

Emigration to Italy started from a small district within the town, known as Borşa Centre. Networks played a crucial role from the outset, reducing the costs and risks of (irregular) migration. This function of facilitating mobility became less critical with the easing of restrictions on movement. Until 2002, migrants required a visa, which could cost up to 2,000 Euro. With the abolition of a visa requirement in January 2002 entry became much easier, with migrants now entitled to stay in a Schengen country for up to three months without a visa (though access to the labour market remained restricted). In order to enter a Schengen country, Romanian nationals required one of three guarantees: an invitation, 500 Euros, or proof of an employment contract and work permit. Easier entry almost certainly contributed to an increase in migration.

As migration to Italy became more widespread, it was also increasingly internalized as a normal life strategy. The strong ties between emigrants to Italy and those in their home town helped to diffuse a number of beliefs and norms associated with migration. Indeed, migration to Italy appears to represent a fairly classic case of a normative culture of migration. International migration has become widely accepted as a feasible and desirable way to supplement income and enhance one's social status at home. The Borşeni who have moved to Italy are locally dubbed 'the Italians'. They are generally associated with hard work and prosperity, and as one interviewee put it, they are considered to be 'more serious' workers. From focus groups, it emerges that young people have internalised migration as a 'rite of passage' (Kandel and Massey 2002, p. 982), a notion that also extends across age groups, professional and social groups, and gender. Indeed, Italian emigration now includes people of all age groups, ranging from seventeen to forty-five, and in some cases families move with younger children. 
Most migrants describe their migration to Italy as a means of building a better life back in Borşa. They plan to return, and send remittances to build houses and invest in the community. These investments are strong markers of their economic status in Borşa, and a source of prestige. This is illustrated in interviews with some of the families and friends of emigrants in Italy. Ioan, a sixty-four-year old man, former miner with three children working in Italy, told us about one of his sons:

Yes, he has a beautiful house, he has a car worth 30,000 Euro, that's one billion two thousand. He has a good place to work. He went there to make money to buy a car, build a house. Maybe he will stay a bit longer; he has his own enterprise, his people.

An official from the town hall's department of urban planning told us that the number of permissions to build houses in Borşa increased sizeably after 2000, to around 150 per year. Emigrants from Borşa had by then accumulated enough money to invest in building new houses.

Migrants to Italy tend to return on a regular basis, typically coming back for the August summer holidays. Many drive back in their new cars; a large number get married, with reports of up to ten weddings per week over the summer. Their life in Italy revolves around ties with family and friends from their home community, and they show little sign of wanting to integrate in Italy. There are widely available transport links to facilitate this circular movement. Indeed, people generally consider Italy to be within a reasonable distance, and they call the buses going there 'cabs'. A journey to Italy costs as little as 100 Euros, and there are buses leaving every Thursday and Friday. There is also a well-developed system for sending packages home. Emigrants from Borşa have a meeting place in Milan where they can send back packages to those leaving for Romania by 'cab'. The 'Italians' have even constructed a sign-post in Milan that designates their neighbourhood as 'Borşa'. 
While emigrants to Italy generally consider their stay to be temporary, many end up postponing their return, and appear to have consolidated a routine of continuous circulation. Some have even set up firms that connect places of origin and destination, thereby facilitating transnational ties. For example, several construction firms in Milan employ workers from Borşa. As Ioan commented about his son:

Are his employees from the Borşa?

Yes, only from here. People are asking him to take them and he can't, he can't take everybody, and there are taxes to pay there too.

Migration to Italy has had significant impacts on the home community. Almost every household includes at least one person who has an experience of migration. Families that have a member who has migrated benefit from regular remittances, and allow their investments to be managed by a family member based at home - for example, managing the construction of a new house, or taking care of the children. Remittances have also generated the creation of many small businesses in Borşa. For example, there is a new Italian style bar with various types of coffee, opened by a migrant who returned to Borşa from Italy. There is even an Italian restaurant that has been opened by an Italian who moved to Borşa - he explained that he likes the people and town. In short, transnationalism between Italy and Borşa seems to be widespread and well consolidated as a life strategy for residents.

\section{Migration to the UK}

Emigration to the UK started somewhat later, and has been less widespread. Because of the visa requirement (only abolished in January 2007), entry into the UK is much more difficult, and migrants have had to devise multiple strategies for irregular entry. The first departures recorded were between 1993-4, with a slow increase until 1996. In 1997, approximately 
twenty to thirty people from Borşa lived in London. Since then, migration has increased, reaching a high point between 2000-2002. Over this latter period, a large number of people travelled to London with the support of smuggling networks that facilitated irregular entry into England. After 2002, people began to fall back on individual strategies, in most cases being smuggled into England via France on trucks or ferries, or via the Eurostar. At the time of conducting the interviews, there were an estimated 300-400 people form Borşa in the UK, most of these in London.

In comparison to the case of the 'Italians', migration to the UK is dominated by young single males (though there are some women). Their mobility can be characterized as a more traditional form of labour migration. They migrate to London to find work and earn a higher wage, and return to their home community only rarely. Most intend to settle in the UK, and are keen to integrate with the local population, rather than socialize with other Romanian emigrants. This can be partly attributed to the higher risks of entering and being apprehended. As Traian, a 27 year old male migrant to the UK told us,

The only problem with this country is that it has a bureaucratic and conservative system in terms of the procedure for becoming legal. It is very difficult. This is a problem for many, and they get caught there for years.

In this sense, even migrants intending to stay on a temporary basis find that their situation becomes more permanent. They find themselves forced to stay at the place of destination. As 29-year old Silvia, who is herself a migrant now, commented about her husband's situation:

He did not have any kind of papers. He could not risk coming back in the country and not being able to return to the UK. Four years he stayed like this.

However, lack of ties with Borşa does not appear to be solely explained by the difficulties of (re)entering the UK. Marius, a 30-year old migrant, told us that even after having become legal in the UK, he did not feel a necessity to go home: 
During these seven years, have you come home?

No, I could not.

And when did you legalize your residence in the UK?

Three years ago. And I came home twice in the past two years.

Underlying this lack of interaction appears to be a rather different set of expectations about the role of migration in the life plans of emigrants to the UK. Whereas migrants to Italy aim to make money and return home to build houses, those we interviewed who had moved to the UK appeared to be more open to alternatives, or 'what the future will bring'. Traian commented,

I do not just want to work, make money and return. I want to make a better life for myself. And so I made new friends once I was there. My girlfriend is from Norway. And I learned a lot from her.

Learning English is also seen as a worthwhile investment, one that will broaden job opportunities for skilled migrants. Migration is in some senses an end in itself, rather than a step towards a future in Borşa. Emigrants return home mainly to visit their parents. Their efforts at integration are focused on the destination, where they are keen to make friends with British nationals or migrants of other nationalities. This is further reflected in the tendency not to invest money in property in Borşa. Where emigrants to London do invest in their home country, this tends to take the form of speculative investments in the closest large city, Cluj, where people buy apartments that they can then rent out.

Related to these rather individualistic strategies is a striking lack of close social networks between Borşeni or Romanian emigrants in the UK, or between emigrants and those left behind in Borşa. Traian exemplified this well when he told us:

If you stay with your co-nationals you do not get too far. 
Traian is a twenty-seven-year-old migrant, who was among the first to migrate from Borşa to the UK. Although he does visit home regularly, he tries to stay away from old friends and colleagues, and more generally from people who could ask him for help. He remarked that others try to be friendly in order to elicit support in getting to London, and he dislikes the idea of people depending on him for help. This attitude is confirmed by other interviews. People admitted that they tend to avoid talking to other people from Borşa about their stay in the UK, because they consider it to be very difficult to help other people in the UK. Migrants from Borşa to the UK are 'on their own', not just in terms of how they make their trip, but also in the process of finding a job or accommodation. As Traian commented:

Are there people who asked you to help them leave?

Yes, there are. In a community you get to rely on others and be asked for help. But I see no point in it. I think it makes no sense, so I had to refuse, but at least I want to refuse nicely. What I dislike a lot is the attitude of our co-nationals in terms of appreciating help. They take it for granted, as if they deserve it. And this is what I do not really understand and that is why I avoid living with them.

The same holds for mutual assistance at the destination. When asked who helped them to find a job or apartment, migrants to London refer to more formal institutions such as letting agencies or recruitment agencies, and do not mention other co-nationals. Moreover, they try to make friends with English nationals who will be in a better position to provide them with a job recommendation. As twenty-five-year old Mihnea commented on the process of finding a job:

I did a course; you did not need to have papers to follow courses. And so slowly I did things that helped me, that helped me get better. And I made friends from there that put in a good word for me. This is very important.

Traian contrasted this tendency with the situation of Romanians in other destination countries: 


\section{Explaining the Divergence: Culture, Utility and Conditions of Inchsion}

\section{The limitations of existing accounts}

Earlier in the paper, we introduced three main approaches for explaining patterns of interaction between migrants and communities of origin. The first of these, the cultural embeddedness approach, appears to capture many of the features of emigration to Italy, with the emergence of a clear culture of migration which has a strong normative impact on behaviour. Emigration is considered to enhance income and status, and is associated with successful and resourceful members of the community. This in turn shapes patterns of crossnational ties, with migrants motivated to retain strong economic and social links, sticking closely with fellow townspeople abroad, and returning on a regular basis and investing in the home community.

If we turn to the UK case, however, the cultural embeddedness account appears to be seriously challenged. While migrants to both destinations were socialized into a similar culture of migration, those that moved to the UK did not seem to retain any sentimental ties to co-nationals or their place of origin, nor did they consider such interaction would enhance their social status. Instead, they rejected ties with co-nationals in favour of developing links with host country or other European nationals. They did not invest substantially in property or businesses in Borşa, but rather chose to invest in a larger town nearby. Moreover, most 
stressed that the main reason for (less frequent) trips home was to visit parents, rather than to sustain social ties with the community or origin. Thus there is no evidence that their social interactions were influenced by the culture of migration assumed to shape the behaviour of those who moved to Italy.

How can we account for this apparent anomaly? One option would be to look to theories of transnationalism to account for the divergence. We mentioned earlier that the transnationalism literature had made some attempt at defining the conditions for the emergence of transnational ties. Typical accounts include geographical distance and ease of communication; causes of mobility (voluntary or forced); and integration policies in host countries. However, many of the variables that purport to explain the divergence are constant in the case of the two emigration flows from Borşa. First, emigration to both the UK and Italy emanated from people with a similar cultural and social profile, and with similar motivations for migration. To be sure, migrants to London were predominantly young males, and this may suggest a propensity to be more autonomous and less dependent on networks with fellow Borşeni. But the cohort of emigrants to Italy also included young males with a similar profile, who - once in Italy - followed a markedly different trajectory. This suggests that the profile of emigrants alone cannot wholly explain the divergence. It strongly implies the explanatory role of opportunity structures in the host country. Second, there was no marked discrepancy between the two destinations in terms of proximity or ease of communication. Admittedly, entry into Italy was relatively easier, and this appeared to make some difference to the retention of close ties to the place of origin. But as we saw, respondents enumerated other reasons for their lack of contact with places of origin - it was not merely a reflection of difficulties in re-entering the UK, but a sense that ties with fellow Borşeni (or other Romanians) would not be useful in the place of destination. Finally, neither country offered legal access to labour markets. Italy offered some prospects for regularization, but the 
respondents from Borşa showed little interest in these. And neither host country officially supported the immigration and integration of Romanian nationals. So these conditions do not appear to offer a very plausible or comprehensive explanation for the emergence of a transnational culture of migration in one case, and the avoidance of transnational ties in the other.

This naturally leads us to the question of whether rational choice accounts are better equipped to explain the divergence. And indeed, on first observation, the divergence in patterns of cross-national ties seems to be more explicable in terms of opportunity structures in places of destination. In the case of migration from Borşa to London, migrants seemed to be quite able and willing to adjust their strategies and use of migrant networks to opportunities in the host society. Circular movement and the retention of strong ties with the community were discouraged by restrictions on entry. Even more importantly, immigrants found that their best chances for integrating into the housing and labour markets lay in developing links with non-Romanians. The retention of ties with fellow Borşeni was seen as burdensome, an impediment to getting on in the place of destination. This contrasted with the case of emigration to Italy, where migrants clearly saw advantages in retaining close ties. Networks with fellow townspeople were seen as facilitating employment and social integration in the place of destination; and continued ties with the place of origin provided a source of social affirmation, enhancing emigrants' status on return.

This rational choice notion of differential opportunity structures is fine as far as it goes. But it cannot adequately explain why networks of co-nationals were so effective in facilitating integration in one case, but not the other. One possible explanation may be the sheer size of the Borşa community in Milan. Arguably, the estimated 300-400 Borşeni in London were too thin on the ground to be of much use in facilitating integration. However, literature on networks suggests that there is no obvious reason to suppose that the size of the expatriot 
community will be positively correlated with the utility of maintaining contacts with them. Indeed, there is some evidence that large numbers of immigrants in one place can dilute solidarity and enforceable trust within networks (Trinci 2006: 385-6). Well-selected contacts and smaller networks could potentially be more helpful. And indeed, the Borşeni in London were not attributing their lack of interest in such contacts to the limited numbers of Borşeni or the difficulties in locating them, but rather to the limited usefulness of drawing on assistance from fellow townsfolk or co-nationals to help them access jobs, accommodation, language skills and so on.

So while the rational choice account is indeed correct in locating the divergence in differential opportunity structures, it fails to conceptualize or explain the structural conditions producing this divergence. In other words, it lacks a theory of the societal conditions that shape migration strategies, and especially the role of migrant networks. As we shall argue, this deficiency can be best elucidated by examining a number of problems with rational choice accounts of social networks.

A systems theory account of social networks

Here we would like to turn to recent contributions of Michael Bommes and Veronika Tacke (2006a; 2006b), which have critiqued prevalent theories of social networks. The target of their critique is network theory in general, but, as we shall see, the argument is highly pertinent to the discussion at hand. There are two, related, steps to their argument. First, Bommes and Tacke argue that network theory fails to specify what distinguishes networks from other forms of social connections. On the loosest definition, social networks are taken to refer to a set of connectivities between different social addresses. A network simply denotes any set of persons who are communicatively accessible to an individual. Bommes and Tacke (2006a) 
argue that this broad definition has no analytical bite, since it remains at a highly generalized level of description. They suggest that what should distinguish networks from other sets of relations is their reflexive element: addresses are relevant where they are perceived as potentially mobilizable for certain purposes. So their conception of networks would include two conditions: (a) the existence of a set of connections characterized by the availability of addresses; and (b) an expectation that these addresses may be mobilized in the future for particular purposes.

The second point is that this potential for mobilization only becomes relevant in certain types of societies: namely, modern societies that are separated into functionally differentiated systems. Bommes and Tacke argue that in pre-modern societies, there was no need for networks in the sense defined. In such stratified societies, the societal inclusion and participation of individuals was conditioned by their birth and status, specifically class, family, affiliation or profession. With modernization, this 'causal primacy' of social structural positions was replaced by a rather different set of requirements for societal inclusion. In modern societies, inclusion is conditioned by the ability to integrate into functionally differentiated spheres: education, welfare, health, the economy, politics, law, family, and so on (Luhmann 1982). Status and affiliation are largely irrelevant to the formal criteria for inclusion into these systems. In most systems, participation is determined by a combination of generalized and inclusive criteria (all residents or all citizens), and specific characteristics or problems that are pertinent to the functions of the system in question (being a child, becoming sick or unemployed, requiring legal redress, and so on).

However, access to new systems can be facilitated by contacts with those already integrated into the system in question. Existing members of a system can provide information or contacts that can improve chances of access, or enhance the quality of service or attention received. For example, a work colleague can recommend a good doctor, or a member of the 
squash club can put you in contact with someone letting accommodation. And this is where networks become relevant. 'The crucial and initial point of network emergence is the observation that addresses - the capabilities they represent in communications - can be combined' (Bommes and Tacke 2006b, p. 5). In other words, social addresses can be mobilized to facilitate access to other systems. Indeed, 'addresses gain social contour and individuality only from an individual's current inclusions and exclusions' in particular systems (ibid., p. 6). The utility of networks derives from their potential to facilitate societal inclusion.

This account can help make sense of the divergent forms of migrant networks in the case of migration to Italy and the UK. In the case of Italy, we observed the predominance of rather traditional forms of social ties. The close linkages between migrants abroad, and between migrants and the community of origin, assumed a primacy of ethnic identity and affiliation. Inclusion in these networks appeared to be determined first and foremost by membership of a particular community of shared culture and values. Moreover, these ties were not just instrumental to facilitating movement or integration, but were performing other social psychological functions: the diffusion of norms, the consolidation of social roles, and the enforcement of trust. In other words, these ties do not meet the systems theory criteria for what counts as a social network. Instead, they can be characterized as a rather traditional form of social interaction that helped ensure the cohesion and reproduction of the community's values and beliefs.

However, we would like to suggest that the mobilization of these ethnic and kinship ties was not shaped so much by socio-cultural characteristics of the community of origin, i.e. it was not 'imported' from Borşa in any direct sense. Rather, it can be understood as a response to the requirements of integration into an informal economy and parallel social structures. As a number of authors have shown, large segments of the Italian economy, 
welfare system and housing market are characterized by a high degree of informality, and it is into these informal structures that irregular migrants are most likely to integrate (BaldwinEdwards and Arango 1999, p. 2; Sciortino 2004). One feature of such informal structures is that participants typically have recourse to more particularised bases for matching expectations and establishing trust. Within formal, state-sponsored social systems, transactions are codified and enforced by legal arrangements. This stabilizes interactions, reducing the need for personal trust or agreement on shared norms. By contrast, participants of informal systems may need to fall back on features such as shared background or culture as a means of stabilizing interactions. The strong role of kinship and social networks in the Italian informal economy attests to this tendency (Quassoli 1999, p. 216; Trinci 2006). Thus criteria such as shared place of origin or ethnicity assume far more relevance as a basis for all sorts of social and economic interactions.

We can go one step further. The mobilization of such ethnic or kinship criteria for meting out favours or enforcing trust is sustained by transnational patterns of mobility. The maintenance of strong ties and circular movement between places of origin and destination helps underpin and renew the relevance of geographical and cultural ties as a basis for mutual support. Indeed, such transnational links may even increase the salience of such identitybased criteria within the place of origin. The ethnic or kinship bonds mobilized in the informal economy in Italy may in this sense be 're-imported' into Borşa, with the resurgence of a more self-conscious identity and bonding between emigrants and their friends and family left behind. Indeed, this reverses the expectations of the cultural embeddedness thesis. It implies that patterns of adaptation in places of destination can shape cultures of migration in places of origin (rather than vice versa).

The case of the UK, by contrast, provides a clear example of how networks operate within functionally differentiated systems. In this case, migrants attempted to establish social 
networks that could facilitate integration into different systems. It was quite evident that inclusion would require the mobilization of addresses according to their usefulness in facilitating integration into the systems of housing, or employment, or health. The logic of network construction was not based on any special expectations of reciprocity deriving from ethnic origin or location of origin. Indeed, this basis for social ties was explicitly rejected as unhelpful. Rather, the use of networks reflected a primacy of the need to solve a problem of inclusion.

\section{Conclusion}

The case of emigration from Borşa provides a challenge for theories of the factors shaping cross-national ties between emigrants and communities of origin. It constitutes a case in which two groups of migrants with a similar socio-economic and cultural profile appear to have developed quite divergent patterns of social ties and networks. While emigration to Milan involved the emergence of a strong culture of migration and transnationalism, emigration to London was characterised by decidedly individualistic decision-making and the avoidance of networks of co-nationals. This divergence, we argued, could not be fully explained by any of the three theories outlined in the first part of the paper: cultural embeddedness, transnationalism, or rational choice theories of migrant networks. Of the three approaches, rational choice accounts appeared best equipped to explain how opportunity structures in host countries might influence divergent strategies. However, we argued that this account could be usefully supplemented by drawing on recent literature on systems theory, which sought to explain different patterns of social interaction in terms of the conditions for incorporation into social systems. On this account, social networks derive their relevance 
from the need to mobilise contacts to facilitate integration into functionally differentiated systems such as labour and housing markets, education and health.

Building on this account, we suggested that divergent patterns of social ties of migrants to Italy and the UK could be explained in terms of the different conditions for societal inclusion in the two destinations. In the UK, societal inclusion was achieved through participating in formal systems, access to which was best facilitated through contacts with non-Borşeni. By contrast, migrants to Italy needed to develop patterns of social interaction that enabled them to integrate into informal social and economic structures, circumventing official, state-sponsored structures. This encouraged them to fall back on identity based criteria - specifically their status as Borşeni - as a basis for stabilizing social relations and enforcing trust. Arguably, the mobilization of these characteristics provided an added motor for transnationalism: intensive exchange with Borşa helped keep alive the source of, and ostensible rationale for, such bonds. As we noted, this could imply a reversal in the direction of causality posited by the cultural embeddedness approach: social interactions in the place of destination may influence cultural norms in the place of origin, rather than vice versa (though clearly more research is needed on this).

Our tentative conclusion is that divergent patterns of migration may at least partially be explained by the modes of societal inclusion in different places of destination. To be sure, such divergences are not the sole determinant of this difference. As noted earlier, variation in the ease of entry into the two countries emerged as an important variable explaining the divergence, in line with the expectations of theories of transnationalism (Portes 1999). However, we would contend that this account could be usefully supplemented by a theory of the different requirements of social inclusion in host countries. To be sure, our empirical study was limited in scope, and certainly insufficient to establish any hard and fast conclusions about the superiority of different theoretical approaches. But it does suggest the 
potential relevance of systems theoretic claims about the role of host society conditions in shaping migrant networks. The next step would be to develop a typology of modes of societal inclusion, extending the categories beyond the two rather simple 'types' discussed in this article. This could provide a basis for more extensive empirical research on how these structures shape patterns of mobility, and especially patterns of transnationalism and migrant networks.

\section{References}

BALDWIN-EDWARDS, MARTIN, and ARANGO, JOACHÍN. 1999. 'Where Free Markets Reign: Immigrants in the Twilight Zone', pp. 1-15 in Martin Baldwin-Edwards and Joachín Arango, Immigrants and the Informal Economy in Southern Europe, London: Routledge.

BOMMES, MICHAEL and TACKE, VERONIKA. 2006a. 'Das Allgemeine und das

Besondere des Netzwerkes', pp. 37-62 in Betina Hollstein and Florian Straus (eds), Qualitative Netzwerkanalyse. Konzepte, Methoden, Anwendungen, Wiesbaden.

---- 2006b. 'Luhmann's Systems Theory and Network Theory', pp. 282-304 in David Seidl and Kai Helge Becker (eds), Niklas Luhmann and Organization Studies, Kopenhagen.

BOSWELL, CHRISTINA. 2008. 'Combining Sociology and Economics in Migration Theory'. Journal of Ethnic and Migration Studies, Vol. 34, No. 4, pp. 549 - 566.

EPSTEIN, GIL, and GANG, IRA N. 2004. 'The Influence of Others on Migration Plans'. IZA Discussion Paper Series, no. 1244.

EVERGETI, VENETIA and ZONTINI, ELISABETTA. 2006. 'Introduction: Some Critical Reflections on Social Capital, Migration and Transnational Families'. Ethnic and Racial Studies, Vol. 29, No. 6, pp. 1025-1039. 
FAIST, THOMAS. 2000. The volume and dynamics of international migration and transnational social spaces, Oxford: Clarendon Press.

FUGLERUD, OIVIND and ENGEBRIGTSEN, ADA. 2006. 'Culture, Networks and Social Capital: Tamil and Somali Immigrants in Norway', Ethnic and Racial Studies, Vol. 29, No. 6, pp. 1118-1134.

GLICK-SCHILLER, NINA, BASCH, LINDA and SZANTON BLANC, CRISTINA (1995). 'From Immigrant to Transmigrant. Theorizing Transnational Migration', Amthropological Quarterly, Vol. 68, No. 1, pp. 48-63.

GRANOVETTER, MARK S. Economic Action and Social Structure. The Problem of Embeddedness', American Journal of Sociology, Vol. 91, pp. 481-511.

HEERING, LIESBETH, ROB VAN DER ERF, and VAN WISSEN, LEO. 2004. 'The Role of Family Networks and Migration Culture in the Continuation of Moroccan Emigration: A Gender Perspective', Journal of Ethnic and Migration Studies, Vol. 30, No. 2, pp. 323 337.

KANDEL, WILLIAM and MASSEY, DOUGLAS S. 2002. 'The Culture of Mexican Migration: A Theoretical and Empirical Analysis', Social Forces, Vol. 80, No. 3, pp. 981-1004.

KIVISTO, PETER. 2001. 'Theorizing Transnational Immigration: A Critical Review of Current Efforts', Ethnic and Racial Studies, Vol. 24, No. 4, pp. 549-577.

LEVITT, PEGGY, DEWIND, JOSH and VERTOVEC, STEVEN. 'International Perspectives on Transnational Migration: An Introduction', International Migration Review, Vol. 37, No. 3 , pp. 565-575.

LUHMANN, NIKLAS. 1982. The Differentiation of Society. New York: Columbia University Press.

---- 1995. Social Systems. Stanford: Stanford University Press. 
MANSKI, C. F. 2000. 'Economic Analysis of Social Interactions', Journal of Economic Perspectives, Vol. 14, No. 3, pp. 115-136.

MASSEY, DOUGLAS S., ARANGO, JOAQUIN, HUGO, GRAEME, KOUAOUCI, ALI, PELLEGRINO, ADELA and TAYLOR, J. EDWARD. 1998. Worlds in Motion: Understanding International Migration at the End of the Millennium. Oxford: Clarendon Press.

PORTES, ALEJANDRO. 1999. 'Conclusion: Towards a New World - the Origins and Effects of Transnational Activities', Ethnic and Racial Studies, Vol. 22, No. 2, pp. 463-78.

PORTES, ALEJANDRO, GUARNIDO, LUIS E. and LANDOLT, PATRICIA. 1999. 'The Study of Transnationalism: Pitfalls and Promise of an Emergent Research Field', Ethnic and Racial Studies, Vol. 22, No. 2, pp. 217-37.

PORTES, ALEJANDRO. 2003. 'Conclusions. Theoretical Convergences and Empirical Evidence in the Study of Immigrant Transnationalism', International Migration Review, Vol. 37, No. 3, pp. 874-892.

QUASSOLI, FABIO. 1999. 'Migrants in the Italian Underground Economy'. International Journal of Urban and Regional Research. 23:2, 212-31.

RADU, DRAGOS. 2008. 'Social Interactions in Economic Models of Migration. A Review and Appraisal'. Journal of Ethnic and Migration Studies, Vol. 34, No. 4, pp. 531-48.

SCIORTINO, GUISEPPE. 2004. 'Between Phantoms and Necessary Evils: Some Critical Pointsin the Study of Irregular Migrations to Western Europe'. IMIS-Beitraege. 24, 17 43.

STARK, ODED, and BLOOM, DAVID E. 1985. 'The New Economics of Labor Migration', International Migration Review, Vol. 72, No. 5, pp. 173-178.

STARK, ODED. 1991. The Migration of Labor. Cambridge: Blackwell. 
TRINCI, SIMONE. 2006. 'The Contribution of Networks to Immigrant Insertion into the Informal Economy: Some Findings from Tuscany'. International Journal of Sociology and Social Policy, 26:9/10, 385-96.

VERTOVEC, STEVEN. 2003. 'Migration and Other Modes of Transnationalism: Towards Conceptual Cross-Fertilization'. International Migration Review, Vol. 37, No. 3, pp. 641655.

\section{Acknowledgements}

The authors would like to thank Michael Bommes, Tim Elrick, Alistair Hunter and Lynn Staeheli for their very useful comments on earlier drafts.

\section{The Authors}

CHRISTINA BOSWELL is Senior Lecturer at the School of Social and Political Studies, University of Edinburgh.

ADDRESS: 15A George Square, Edinburgh EH8 9LD, UK. Email:

christina.boswell@ed.ac.uk

OANA CIOBANU is a researcher at the Migration Research Group, Hamburg Institute of International Economics.

ADDRESS: Heimhuderstrasse 71, 20148 Hamburg, Germany. Email:

ciobanu@hwwi.org

Word Count: 7,999 